\title{
The Role of Academic Libraries in Research Data Management: A Case in Ghanaian University Libraries
}

\author{
Abankwa Frederick*, Yuan Run \\ School of Research Institute of Scientific Information, Jiangsu University, Zhenjiang, China \\ Email: *abankwafrederick2025@gmail.com
}

How to cite this paper: Frederick, A. and Run, Y. (2019) The Role of Academic Libraries in Research Data Management: A Case in Ghanaian University Libraries. Open Access Library Journal, 6: e5286. https://doi.org/10.4236/oalib.1105286

Received: February 25, 2019

Accepted: March 25, 2019

Published: March 28, 2019

Copyright $\odot 2019$ by author(s) and Open Access Library Inc.

This work is licensed under the Creative Commons Attribution International License (CC BY 4.0).

http://creativecommons.org/licenses/by/4.0/ (c) (i) Open Access

\begin{abstract}
Seeking information is of the great key for both researchers and academic librarians and for that matter getting data plays a key role. The act of sharing, preserving, collecting, disseminating, and managing of data with respect to research data is of the essence in our current system of retrieving information. This has been made possible by the collaboration with information communication and technology for both researchers and academic librarians. Scholars are now producing, disseminating and storing digital data in much larger volume than the text. Management of research data is a major challenge for many universities in Ghana. In case, having access to such data is really difficult because some data are not stored in libraries. The study reveals that some academic libraries are beginning to provide frameworks for these services with some degree of success as policies are being formulated. Also, infrastructures are being set up, and library staff trained, and awareness and advocacy campaigns held with academic staff and researchers. The study seeks to explore academic librarians' perceptions of their roles and involvement in RDM support services. In view of that, the researchers used the qualitative method and gathered data using semi-structured interviews. Thematic analysis method was used to analyze the data collected. A sample of 116 librarians was targeted for the survey in the data collection process. Out of one hundred and sixteen (116), only eighty-one (81) agreed to participate. The findings reveal that academic libraries in Ghana need to improve their technical skills and competency sets through training and other capacity building program. Based on the findings recommendations were also provided which can help major Ghanaian academic libraries to improve.
\end{abstract}

\section{Subject Areas}

Library, Intelligence and Philology 


\section{Keywords}

Research Data Management, Research Data Services, Academic Libraries, E-Science, E-Research

\section{Introduction}

Management of research data is a service area of increasing interest to libraries. Science has entered a fourth paradigm that is more collaborative, more computational, and more data-intensive [1] than the previous experimental, theoretical, and computational paradigms. The emerging scientific paradigm is called e-science or e-research [1]. In many universities, vast quantities of born-digital RDM are now being produced in a wide variety of form. This help in creating the so-called volume, variety and velocity data challenge. The need to develop infrastructure, policies, and service in many institutions in Ghana to manage data has generated data deluge. The aim of assisting researchers is collecting, creating, analyzing, manipulating, storing, preserving and transporting datasets. In another view, there may be a need to share some data either among specific groups or open. There is a growing in spite of this challenges of sharing data widely, therefore, creating benefits which includes allowing the verification of research outcomes, gathering scientific actives, and enabling contribution of wider data sharing and facilitating data by others research. Funders of Research, need to encourage scientific good practice in order to achieve greater value in their research they have been sponsored. This will help to increase to require a standard of data management and sharing data. For higher education institutions, research data represent a valuable institutional asset, which has the potential to be reused beyond the active research phase [2].

Among universities and other organization, a different approach of RDM is being developed and other different stakeholders have become involved, including helping service staff as well as faulty themselves. Design of research data service has helped in contributing significantly in some general activities, in view of that university libraries have moved into space and are increasingly seen in major contributors to RDM. In Ghana, many research funders instructed that applicants produce a data management plan as part of their research proposal and are aimed to create a design-in data sharing and reuse wherever possible. There is a patchy coverage of subject-specific data repositories and another data service (Paul Simmonds et al., 2011) and a strong case for open data [3]. The institutions are solely responsible for addressing the challenges in two ways, short and long terms. The higher institutions in both developed and developing countries are developing infrastructures to support researchers to manage their data. Data could exist in the file and as physical on the computer of researchers or terabytes of data on shared servers. University worldwide is focusing on research activities which have tremendously enhanced the production of research data. A number 
of researchers and professionals have an important part to play.

Due to the ongoing research discussion, this paper analyses how Ghana libraries were exploring this role. The paper data were gathered from a survey of Ghana detailing the ways in which libraries are involved in RDM and the extent to which the development of RDM services is a strategy for them.

\subsection{Statement of the Problem}

Research data management has become an important issue in every research institution, especially in Ghana. Research could mandate researchers to write up RDM and the majority supports the idea to share research data openly. A lot of researchers often share and use colleagues' research data in their work. Positive attitude about researchers' towards sharing and archiving of research data indicates that there are challenges that researchers encounter in their attempt to comply with the mandate from the research council. The issue will be ensuring that data can be stored in a secure manner while remaining accessible and not inhibits, researcher careers. There are a lot of factors that inhibit researchers to perform data management work. On the side of technical in nature, researchers do not have the technical skills to do metadata work. Also, there are no time constraints to organize the data, no incentives for researchers who have agreed to share their data and lastly no standardized storage infrastructure. In the field of research support, academic libraries provided to researchers and have been involved in preserving, managing and providing access to information. Academic librarians and libraries should provide a role in RDM to support on behalf of the researchers. This is will minimize the stress that researchers face as they try to fulfill the mandate of the research council.

\subsection{Aim and Objectives}

\subsubsection{Aim}

The overarching aim of the study is to explore academic librarians' perceptions of their roles and involvement in RDM support services.

\subsubsection{Objectives}

The researcher conducted a present study with the objectives:

$>$ To identify factors that hinder academic libraries from providing RDM;

> To explore the librarian's awareness of RDM mandate;

To analyze the roles that are suitable for academic libraries in RDM work.

\subsubsection{Research Question}

To enable the researcher to achieve the mentioned objectives, this study shall seek to answer the question of how do academic libraries perceive their role and responsibilities in RDM support services at the Universities in Ghana.

\subsubsection{Value of the Study}

The Research Council in Ghana and institution could find this research significance which makes strategic decisions and formulates related research policies 
for the organizations. It includes University libraries staff, directors, institutional repository managers and other stakeholders who are responsible to establish systems and assign roles for the setup of RDM support services. The findings from this study may inform the University management and relevant stakeholders on the RDM capability and support.

\section{Research Context}

Research Data Management as a field of scientific inquiry is still evolving. As a domain within the emerging research paradigm of e-Science or e-Research, $\mathrm{RDM}$ is increasingly attracting more attention from government, funding bodies, academic and research institutions and researchers [4] for its value and prospects for advancing scientific research. In e-research, it's the primary research data that much often be managed, made accessible and curated [5]. It's a broad concept that includes processes undertaken to create organized, documented, accessible, and reusable quality research data [6]. Another argued that data management involves a number of stakeholders, both within and outside the university community [7]. The academic library is especially important because it occupies the unique position, as both a facility with staff who have expertise in many of the issues surrounding RDM and a campus-wide service with relationships among these many stakeholder groups, that favorably positions it to lead the RDM effort. It concerns the careful handling and organization of research data throughout the entire research lifecycle with the aim to carry out research activities efficiently and allow collaboration with others. It's the planning, organization, and preservation of the evidence that underpins all research conclusions. Good data management ensures data is safely stored, findable and can be used to reproduce findings. Such activities and processes are needed for a wide variety of different forms of data ranging from large-scale calculations derived from high-performance computing facilities, through results of scientific experiments, to audio recordings of interviews. It involves decisions about how data will be preserved and shared after the project is completed for instance depositing the data in a repository for long-term archiving and access.

Some researchers have proposed that academic library services are well centered to play an important role in RDM [8] [9]. Some work also was done by scholars such as [10] [11] [12] discuss some of the roles of RDM. Each day, they are generating a huge volume of data. However, the spontaneous growths of volumes of data generated by researchers are hindered by storage infrastructure [13]. Some also further discuss some libraries opportunities and some challenges in developing the capacity and capabilities to carry out RDM. Some research indicated the opportunities and challenges stakeholders encounter in RDM [14]. The metadata expertise plays a key role in both curation and retrieval aspects of the management of data.

The research datasets components have been outlined by the research council as a process of output data storage, archiving with identifiers, Preservation with metadata and access to data and metadata (Figure 1). 


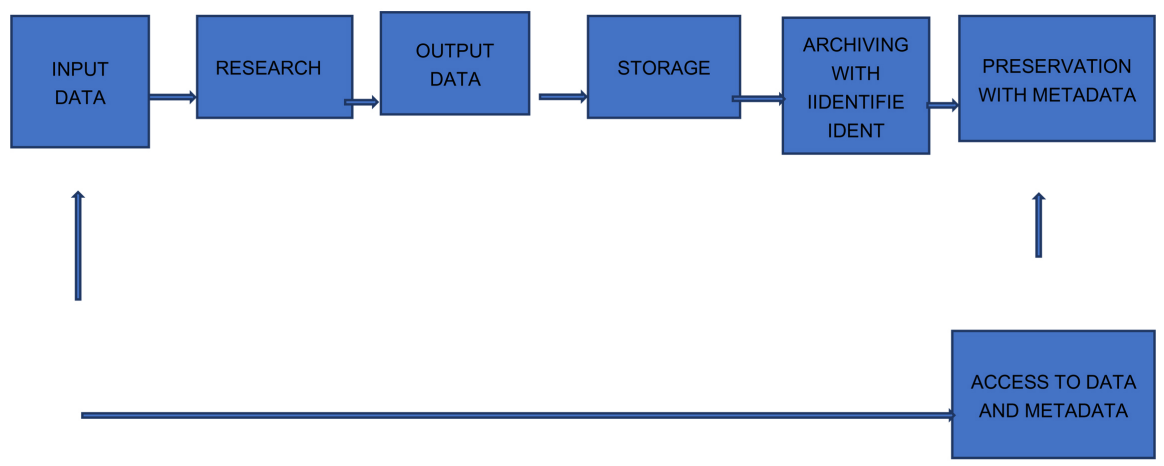

Figure 1. Research datasets components.

There is of the view that providing RDM service and training for librarian provides them with the requisite information about it since they are not given enough time by their institutions to provide data management service (DMS). Librarians are key players for RDM in every organization. Librarians unlike other stakeholders in other organization, they have upon hands with the academia.

In terms of data sharing, librarians of strong inter-organizational make it more effective and efficient between institutions. Furthermore, one made mentioned of numerous opportunities for libraries and some challenges in order to develop the capabilities to carry out RDM [14] [15]. Therefore, there is a need for a library in a wider institutional to emphasizing the need for libraries to work in partnership with IT services and academic staff. A lot of organization and storage of those data were ad-hoc in nature and not focused upon. RDM plans have gained importance as the funding bodies have mandated a lot of researchers and applicant to have in place (Figure 2).

Figure 2 describes various infrastructure and services that universities require to develop to support research data management. This model is used as a guide for academic libraries who envisage initiating effective data management [2]. It addresses all the components to be addressed when delivering RDM services together with a description of the roles and responsibilities of those who may deliver and use them [16].

In view, libraries have adapted to the change by those technologies.

There are so many factors that push many libraries to get started with research data management. Among some includes it offer RDM support, including data management plans for grant applications, intellectual property rights advice and information materials, engage in the development of metadata and data standards and provide metadata services for research data. Create data librarian posts and develop professional staff skills for data librarianship. Promote research data citation by applying persistent identifiers to research data. Among this, some of the roles in RMD include offering advice on funding sources, data analysis advice and advocacy for open access. This evidence provided indicates libraries are doing possible ways to support researcher to make their work easy. There is still ongoing debate as to how the RDM should still position itself because resources such as policy management, infrastructure, and governance 

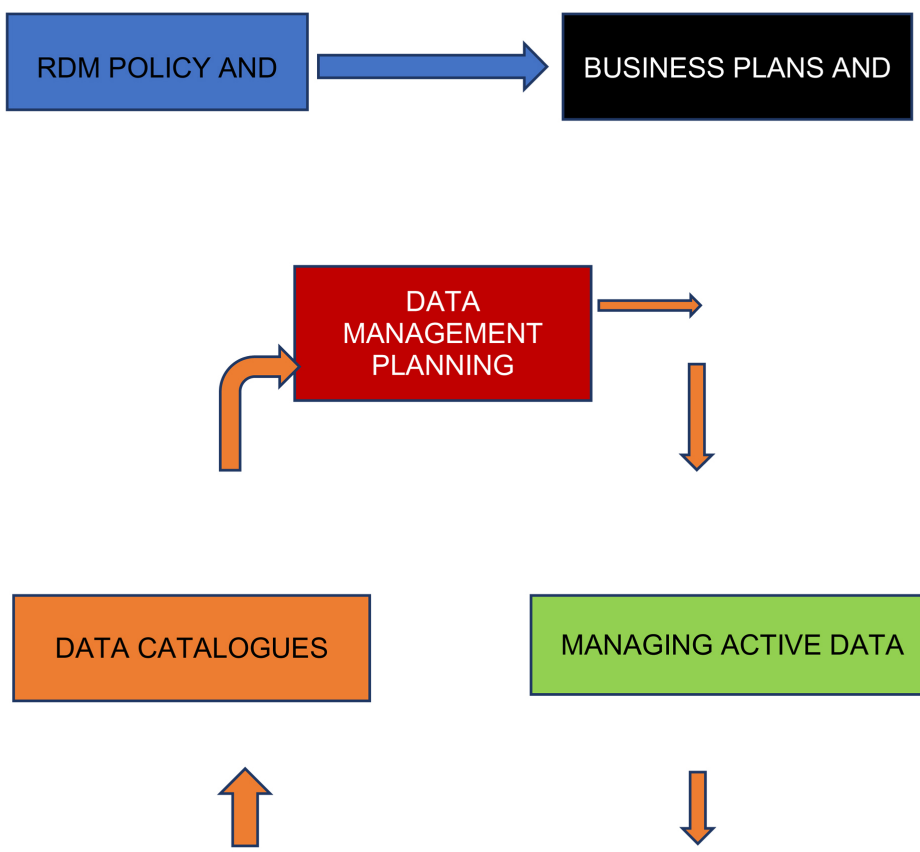

MANAGING ACTIVE DATA

DATA REPOSITORIES

DATA SELECTION

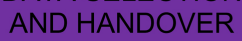

\section{GUIDANCE, TRAINING AND SUPPORT}

Figure 2. Components of RDM Support service by DCC.

development still remain intact. Their challenges faced by librarians in case of RDM. One of such is IT technical know-how. This implies that a lot of librarians do not have this technical eyesight. This may affect domain-specific expertise and could limit their research area. Another aspect is the librarians' information management skills. This could be a challenge in translating research metadata creation or data housekeeping. A lot of researchers lack knowledge about handling data. A survey in 2017 revealed that majority of faculty in Ghana expressed great interest in the curation of data, nearly half of librarians who did not have a plan for data management claimed that they didn't know enough about data management plans. Majority of researchers doesn't see libraries as a place to turn for their RDM requirement. This may due to the fact institutions have been another type of impediment. This is because, with the same institutions, there may be a difference as to what constitute good research data. Therefore, the nature of how data are created and used becomes a problem. Despite the challenges faced by the librarian to mastermind the RDM, there has been a model suggested 
by some authors for libraries [17] [18]. Irrespective of this model, there has been an incentive that has motivated libraries in acquiring RDM capacity [19]. They are multi-faceted and flow from a different source which includes Compliance, Evolving, Institutional strategy, and Researcher demand.

\section{Methodology}

Research design of a study is the overarching strategy or plan of action that a researcher maps out to perform an empirical inquiry [20] [21]. It's a plan and procedures that guide the whole research activity from general assumptions to specific methods and tools for data collection, interpretation, and analysis [22]. The approach of the research was designed to show detailed information to address these research questions. The qualitative research approach was employed. The aim is to explore academic librarians' perceptions of their roles and involvement in RDM support services. Also, the main instrument was a questionnaire. The surveys were drafted in such a way that it examined humans and their relationship with the institutions. Qualitative research approach enables one to study and understand the meanings of one's feelings, actions and underlying principle of behavior between two parties. It's important for researchers to adhere to certain methods of collecting, interpreting and analyzing because research by nature is a multifaceted [23]. The study is centered on the role of Academic Libraries in the RDM process in Universities in Ghana.

Not surprising, academic research libraries, larger schools, and those receiving more grants were more likely to be planning to offer research data management services than other types of academic libraries [24]. About three universities in Ghana academic librarians were used since the researcher aimed to obtain sites that had sufficiently advanced plans to enable them to generate detailed and rich information about RDM activities in the Libraries. Libraries with high enrollment, larger faculty size, and at research institutions were more likely than libraries at smaller schools to be involved in things such as managing RDS technology infrastructure, planning RDS skills development opportunities for staff, and collaborating with other units on campus [24].

\subsection{Sample and Sampling Methods}

The researcher selected Academic Librarians in senior management roles of the various university libraries of higher education in Ghana. The researcher considered it appropriate to select a sample based on the knowledge of the population, its elements, and the purpose of the study. What determines the quality of research is not limited to the appropriate methodology, it's essential that a suitable sampling method is used in research [25]. The institutions were selected from various Universities which include the University of Ghana, University of Cape Coast, Kwame Nkrumah University of Science and Technology (KNUST) and Valley View University. The reason why I selected these schools is that the Librarians have experience and their involvements in $\mathrm{RDM}$ projects are great. A 
sample of 116 librarians was targeted for the survey in the data collection process. A semi-structured interview was employed for the data collection. Surveys were initially distributed in August 2017, with a follow-up in March 2018. In view of that document, the analysis was used as supporting data. In the qualitative studies providing adequate information about the research can be problematic that's the needs of the researcher could change. In view of the interviews, invitation letters were sent requesting for participation, out of one hundred and sixteen (116) only eighty-one (81) agreed to participate.

Due to geographical dispersion, financial difficulties, time constraints, and distance, it was difficult to conduct face-to-face interviews, in view that the survey was done online to help save time. It was done through videoconferencing such as Skype because the main focus was to replace face-to-face by the video call.

Questions were both open-ended and closed-ended this because participants came from a different institution and were either senior library managers or middle-level managers with direct responsibility for RDM. It was arranged as follows:

- Introduction: Questions on the participants themselves, including their institution, role, and personal experience of research.

- Library roles and readiness to provide RDM service: Questions on a range of RDM-related service and activities and the service provided by libraries in supporting RMD service.

- Skills and competencies to provide RDM service: Questions on some level of subject knowledge to support RDM including at least a basic understanding of the disciplinary landscape, norms, and standards.

- The challenges of RDM roles in Libraries: Question on issues encountered when creating, managing, and sharing research data.

- RDM policies:

The questionnaire took between 10 and 20 minutes to complete, depending on the extent to which comments were added. It was designed to encourage responses but not to be onerous.

The survey was targeted at, but not limited to, library staff in Ghana and research institution.

\subsection{Data Analysis}

A total of 81 responses were received and recorded. An analysis method that was used to manage the data gathered from the data collection is a thematic analysis method. This is because it provides a flexible, quick and relatively easy method to learn and do and importantly accessible to novice researchers. The use of thematic analysis method helps researchers in getting to know the data. This can be achieved by listening and re-listening to recorded data as well as through reading of extracts from blogs.

Of the 81 responses, $22(27 \%)$ are from Cape Coast University (Teaching-led institution), 30 (37\%) from University of Ghana (large research-intensive insti- 
tution), 19 (23\%) from KNUST (other research-led institutions) and 10 (12\%) from Valley View University (other teaching-led institution).

From Figure 3, it can be seen that on the bases of awareness of RDM mandate librarians from the University of Ghana had prior knowledge of their roles towards RDM service this because is the oldest University in Ghana. A lot of them are aware of the research council mandate and the formulation of it. Which is followed by cape coast which is been given percentage had 27\%, KNUST, and Valley View respectively.

In terms of the challenges of RDM Roles in Libraries, since the University of Ghana had been in the system for years, they have a lot of expert in relation to RDM. Some mentioned that what the major challenges face is IT which lacks the knowledge in operating Information Technology. Others mentioned that lack of a humanperson in the sense that most of the libraries did not have subject librarians to work in RDM projects. Also, a member of Valley View University stated categorically that, the size of the institution affects the number of staffs required to work in the library. Another challenge mentioned is a financial problem faced by the institution to hired qualified personnel. RDM projects seem expensive in terms of acquiring storage facilities, the software needed. In addition, librarians working in the small university are not exposed to research activities in their institution.

The sample, in particular, includes a very high proportion of University of Ghana (30 out of a total 32), even though this has the benefit of enabling comparisons between them and the rest of the sector. Of the analyzed responses 55 (68\%) had personal experience of research at Masters, 61 (75\%) hold a position on the Library senior management team. Also, 21 (24\%) from IT and library service while 10 (12\%) hold Ph.D. level in Library.

From Figure 4 answers, the question does your institution have a formal research data management policy in place? From the above, 35 (43\%) respondents agreed that yes, they have RDM policies instituted in their institution. Also, 25 (31\%) respondents don't have the RDM policy in place but planned to be instituted the next year 2019. Again, it can be seen from Figure 2 that 14 (17\%) respondents agreed that they don't have the RDM policy in place. Lastly but not

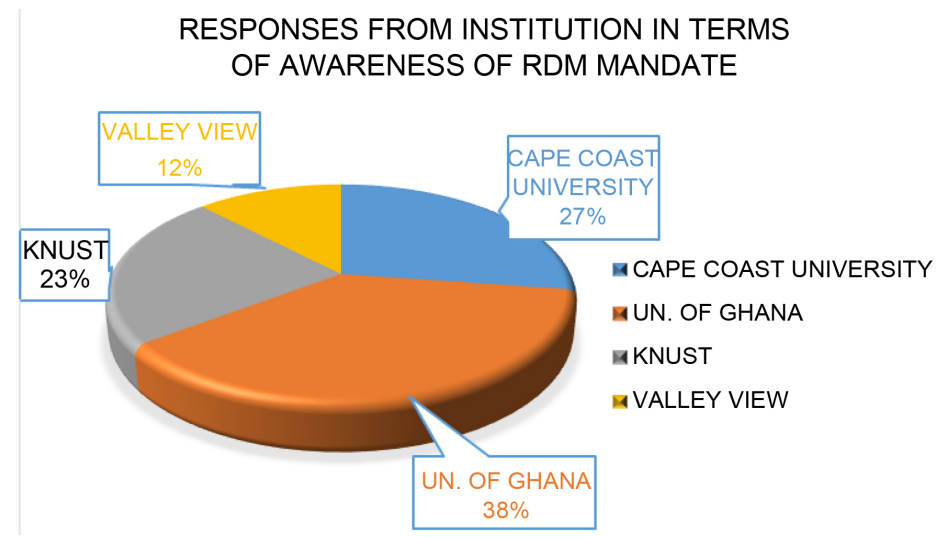

Figure 3. Respondent awareness of RDM. 


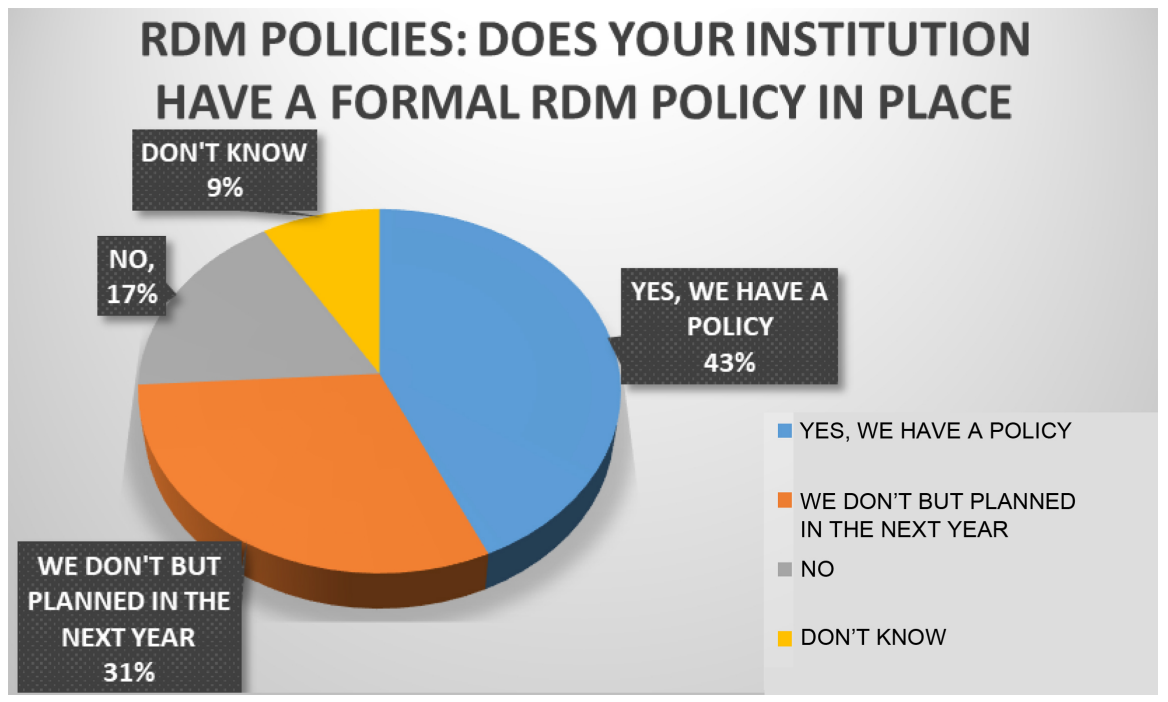

Figure 4. RDM Policies awareness.

least, 7 (9\%) respondent said that they don't know anything about the RDM policy.

On the other hand, with respect to perceived role of Academic Librarians in RDM 60 (74\%) participant mentioned that with respect to advocacy and support faculty should negotiate on legal issues such as copyright agreements in the management of data. The respondent indicated that they know the role played by librarians. The respondent indicated Librarians should work hand-in-hand with IT department and to collaborate with some researchers one added that information about where dataset can be found can be integrated into Library's service in order to create the discovery services.

Again, in providing access to data about 45 (55\%) respondent mentioned that academic librarians' have in-depth skills in setting up institutional repositories. Also, about 20 (25\%) said they had prior knowledge from the time of working at the Library. This implies that there a lot of librarians that don't have ideas in RDM service but have ideas in open access, with little training they can do better. Again 61 (75\%) said, academic libraries should encourage researchers to apply appropriate metadata description tools to describe the datasets so that others can find, use and cite their datasets. It was added that libraries can create overviews of how datasets can be found. Also, 43 (53\%) respondent said that academic libraries should aid researchers to understand metadata descriptions for data sets.

In terms of data collection managing, 67 (83\%) respondent said that Academic Libraries should partner with IT companies for instance Intercom Programming \& Manufacturing Company Limited (IPMC) and Data Kite to develop RDM service because of its technical competence. Also, 76 (94\%) respondent made mentioned that IT lacks the knowledge of the research field. They added that IT needs to have knowledge of the research field to be able to do the curation of the data. About 26 (32\%) respondent indicated with respect to skills and 
competencies is the duty of the librarians to communicate and interpret technical terms to the understanding of users of the software to manage the research datasets.

\section{Discussion of the Research Survey Finding}

The findings were based on the role of academic libraries in research data management among universities in Ghana. From the data obtained it's clearly seen that few academic libraries have started establishing institutional data repositories. This will help to cater for the storage and retrieval needs of their institutions and it will bring about innovation in the academic libraries' services.

Per the survey, it can be found that research council mandates are compulsory for researchers to seek funds to comply. This implies that the response from academic libraries to offer support varies from that of the response from Ghana National Academic Libraries. From the respondent per the survey indicated that some academic libraries have already performed traditional role in managing digital based material. In the event of the open data policy library professionals has declared to inculcate that as a new role. Some respondents agreed that innovations are what caused the RDM policies to be uncertain. Also, about 35 (43\%) respondent gave evidence that some Academic Libraries have institutional policies on RDM. This made Librarian seek advantage to claim core role in RDM. Librarians don't have to wait for policies in order to act but should build experience to enable them get started. Despite the uncertain innovation, Librarians are trying to adopt the new innovation by equipping themselves with training. Librarians have the expertise to capture scientific knowledge as it is being created so it's managed and recorded for later dissemination, but their skills with managing research data vary. In view of that, Librarians need training to effectively lead the application of research data management solutions at their institutions to support all levels of librarians. Per the survey, the respondent got to know that there is a need for them to learn more about RDM practices. Researchers are aware of their policy funders on RDM than their institutional policies [26]. According to the respondent, librarians who work in academic libraries, research data management services are being performed never or only a few times a year. This is due to the fact that it takes into account the planned availability as well as current availability. Therefore the growth in current performance of RDS by librarians can be expected to follow growth in current availability of RDS by libraries. Apparently, they seem to have a positive attitude towards RDM roles. In engaging with research in management of data library is seen as the best service providers within a university.

Considering skills two types were mentioned by the respondent that's technical RDS and informational RDS. According to the respondent, informational RDS is less available in libraries that are technical RDS. The technical RDS required the installation and handling of software and hardware. It's the designing of data systems and infrastructure, database query, metadata and storage of data. On the other hand, informational RDS include communications, advice, and 
training of researchers, team building, negotiation, discovery and retrieval of data sets, copyright, information seeking, and marketing of library services. Per the study, a lot of the respondents were having an idea about the open access project. This implies that they have gained confidence in their activities of open access support services. The result indicated that if the academic libraries partners with IT firms, for instance, IPMC and Data Kite which can provide technical service effectively and support libraries solution it makes the formation of consortium very easy. This indicates there will not be any hindrance technically to initiate research data project. Academic librarians have a long history of supporting the research process. As research has become increasingly data-driven we are seeing an unfortunate gap in competencies and skill sets needed to fully integrate librarians into data management. One technical $\mathrm{RDM}$ issue practice had to do with the provision of archiving, preservation and storage of research datasets which require services of librarians. Libraries can also promote the use of common standards and tools among researchers.

In most academic data service, collecting data has become an important component. We surveyed academic data librarians to discover how they how they identify, obtain and provide access to small data set for their institutions. Per the survey, it was indicated that librarians demonstrated their skills in using discovery tools to enhance data access and sharing. Moreover, the majority of the librarians are aware of what constitutes data storage infrastructures. Also, they are aware of their purposes, application, and description of metadata standards and schemas for efficient storage and retrieval of the dataset.

Per the study, it reveals that the challenges are the universal issues cut across the academic libraries in Ghana. This is because some of the academic libraries find it difficult to initiate RDM services on their institutional level. The study reveals that they lack collaboration between institutional level and national service providers. It was revealed that there are several handcrafted approaches to storing research data by researchers. This is because researchers often preferred to buy cheap storage and to run their own system. Respondent reveals that the storage facilities provided by the universities are much expensive. Also, the infrastructure needed to support in demanding the provision of RDM is inadequate. Respondent reveals that most Ghana universities have not built capacity for storage of data as compared to other institution where they have a repository where every research that goes on, the data is gathered and put in the repository for access by other researchers. And lastly, the study reveals that RDM service demand is uncertain. According to the University of Ghana research Policy, it was revealed that the University recognizes the need to develop systems such as a "meta-database of research materials/data repository" to support RDM. Also, there are inadequate skilled human resources that hinder the attempt to perform RDS. This is because they lack the expertise to perform the task. In view of that one respondent added academic librarian staffs need to be computer literate to be able to take up their role. He added that good communications skill is needed because as they need to assist the researcher their skills of communication should 
be very good. Carlson mentioned that the challenges encountered by librarians seeking to engage in data management and curation issues are found at the individual level (acquiring skills and confidence) and at the organizational (creating a supportive environment) both levels will need to be addressed by libraries seeking to develop data services [27] [28].

The finding reveals that in respect to institutional policies some Universities in Ghana have no specific RDM policy. In November 2012, the University of Ghana Research Policy addresses some critical areas which include Ethics, Intellectual Property, Academic Freedom and Creativity. The study reveals how researchers get to know research-related policies. It was indicated that such policies and guidelines are published on the ORID websites and the links are sent to the university community via an institutional emailing platform.

\section{Conclusions}

Research Data Management service is emerging as an important offering by academic. The overarching aim of the study is to explore academic librarians' perceptions of their roles and involvement in RDM support services, specifically, to identify factors that hinder academic libraries from providing RDM, to explore the librarian's awareness of RDM mandate and to analyze the roles that are suitable for academic libraries in RDM work. Answers to these gave a general understanding of the current situation of the role of Academic Libraries RDM among the Ghanaian Universities. Policymaking, infrastructure requirement, planning may differ from institution to institution in the context of RDM service.

The findings of the study revealed that most of the academic institutions in Ghana don't have a formalized structure and policy to back the activities and responsibilities of academic libraries. It has been revealed that some of the universities in Ghana are currently underdeveloped but with the immense potential for growth. The study revealed that sharing of data has now become worldwide acceptable objectives with most governments mandating Open Access of data and research funded by it. World Bank data opening is an example of the fact that international organizations are also working on opening up access to their data. Libraries as organizations must create an environment that supports the roles and responsibilities of librarians working with data and ensure that librarians receive the training; they need to develop relevant knowledge and skills. In order to fully technical RDM service, libraries need to have the technologically skilled staff or greatly increase opportunities for technology training for their existing staff, which might not be feasible due to resource constraints. Mostly, collaboration is needed in Universities in Ghana to grow RDM service. This will enable them to create a "research data network", including researcher with varied expertise, to address RDM service issues based on multiple discipline-specific needs. One of the discipline-specific networks that the researcher discovered in most of the universities in Ghana is a digital humanity working group, which provides a platform for exchanging ideas, keeping up with trends in the fields 
and focusing on RDM service issues.

Per the study, it has been revealed that most library activity, currently concentrated in areas such as advocacy and policy development, and moving into new areas including the support functions and creation of new systems, still has an important element of provisionality about it. The study also revealed that the Academic Libraries in the Universities in Ghana must find ways to align and partner with other agencies of the university in order to work effectively.

\section{Recommendations}

Researchers recognize the importance of RDM service and data sharing but some are not willing to invest their time in good RMD service and therefore not willing to share their data. This really affects the institutions as a body. The findings of the study give an in-depth analysis of the academic libraries role it plays in Research Data Management service. Based on the findings some recommendations have been proposed for the development of RDM in the Universities in Ghana under study:

- Academic libraries in Ghana should cooperate to set up RDM community to provide on-going skills and development training for their librarians. This will boost their confidence in dealing with the researchers.

- Also, they should provide online service-related course freely for their librarians about data management. For instance, MANTRA: Research Data Management Training hosted by the University of Edinburgh. This provides a good introduction for librarians and researchers alike.

- Policies must be developed for data selection and data retention because not all data can be retained, stored, managed and reuse and criteria for making such a decision should be clearly laid out in the policy.

- Again, national and external level of infrastructure must be constructed to support and supplement institutional effort towards RDM development.

- Furthermore, the universities in Ghana should set aside funding opportunities to help support RDM systems development and service. For instance, institutions that advocates and support research data development and open access initiatives.

- Academic Libraries should initiate RDM service to reduce cost which will encourage the librarians to upgrade themselves.

- Ghanaian Universities academic libraries should learn much from other successful academic libraries from other countries to enable them to provide a solution to their challenges.

- Academic Libraries should work towards establishing a data repository with the capability to link datasets with the corresponding article on both internal and third-party systems.

- Academic Libraries should explore Digital Curation center Data Management Plan Online and University of California Curation center Data Management Plan Tool for developing local requirement and questions for writ- 
ing Data Management Plans.

\section{Conflicts of Interest}

The authors declare no conflicts of interest regarding the publication of this paper.

\section{References}

[1] Tolle, K.M., Tansley, D.S.W. and Hey, A.J.G. (2011) The Fourth Paradigm: Data-Intensive Scientific Discovery [Point of View]. Proceedings of the IEEE, 99, 1334-1337. https://doi.org/10.1109/JPROC.2011.2155130

[2] Jones, S., Pryor, G. and Whyte, A. (2013) How to Develop Research Data Management Services-A Guide for HEIs. Digital Curation Centre, Edinburgh, 1-22.

[3] Boulton, G., et al. (2012) Science as an Open Enterprise. https://royalsociety.org/ /media/policy/projects/sape/2012-06-20-saoe.pdf

[4] Kahn, M., Higgs, R., Davidson, J. and Jones, S. (2014) Research Data Management in South Africa: How We Shape Up. Australian Academic \& Research Libraries, 45, 296-308. https://doi.org/10.1080/00048623.2014.951910

[5] O’Brien, L. (2005) E-Research: An Imperative for Strengthening Institutional Partnerships. 64-77. https://core.ac.uk/download/pdf/143879601.pdf

[6] Van den Eynden, V., Corti, L., Woollard, M., Bishop, L. and Horton, L. (2011) Managing and Sharing Research Data: A Best Practice Guide for Researchers. https://data-archive.ac.uk/media/2894/managingsharing.pdf

[7] Flores, J.R., Brodeur, J.J., Daniels, M.G., Nicholls, N. and Turnator, E. (2014) Libraries and the Research Data Management Landscape Suggests a Broader Role for Libraries and Librarians, including Integration of RDM into Teaching at the Undergraduate Level and in Schools. No. 2010, 82-102. https://www.clir.org/wp-content/uploads/sites/9/RDM.pdf

[8] Tenopir, C., Sandusky, R.J., Allard, S. and Birch, B. (2014) Research Data Management Services in Academic Research Libraries and Perceptions of Librarians. Library \& Information Science Research, 36, 84-90. https://doi.org/10.1016/j.lisr.2013.11.003

[9] Chiware, E.R.T. and Mathe, Z. (2016) Academic libraries' role in Research Data Management Services: A South African Perspective. South African J. Libr. Inf. Sci., 81. https://doi.org/10.7553/81-2-1563

[10] Yoon, A. and Schultz, T. (2017) Research Data Management Services in Academic Libraries in the US: A Content Analysis of Libraries' Websites. College \& Research Libraries, 78, 920-933. https://doi.org/10.5860/crl.78.7.920

[11] Tripathi, M., Shukla, A. and Sonker, S.K. (2017) Research Data Management Practices in University Libraries: A Study. DESIDOC Journal of Library \& Information Technology, 37, 417-424. https://doi.org/10.14429/djlit.37.11336

[12] Perrier, L., et al. (2017) Research Data Management in Academic Institutions: A Scoping Review. PLOS ONE, 12, e0178261.

https://doi.org/10.1371/journal.pone.0178261

[13] Hey, T. and Trefethen, A. (2003) The Data Deluge: An e-Science Perspective. In: Berman, F., Fox, G.C. and Hey, A.J.G., Eds., Grid Computing. Making the Global Infrastructure a Reality, Wiley and Sons, Hoboken, 809-824.

[14] Tsang, D.C. (2014) Research Data Management: Challenges and Opportunities. 
https://ink.library.smu.edu.sg/cgi/viewcontent.cgi?referer=\&httpsredir=1\&article=1 001\&context=lib_events

[15] Lyon, L. (2016) Librarians in the Lab: Toward Radically Re-Engineering Data Curation Services at the Research Coalface. New Review of Academic Librarianship, 22, 391-409. https://doi.org/10.1080/13614533.2016.1159969

[16] Hodson, S. and Molloy, L. (2014) Current Best Practice for Research Data Management Policies. https://core.ac.uk/display/30670815

[17] Lewis, M. (2018) Libraries and the Management of Research Data. In: McKnight, S., Ed., Envisioning Future Academic Library Services, Facet Publishing, London, 145-168.

[18] Corrall, S. (2012) Roles and Responsibilities-Libraries, Librarians and Data. In: Pryor, Ed., Managing Research Data, Facet, London, 141-151.

[19] Bryant, R., Lavoie, B. and Malpas, C. (2018) The Realities of Research Data Management Incentives for Building University RDM Services. 1-26.

https://www.oclc.org/research/publications/2017/oclcresearch-research-data-manag ement.html

[20] Pickard, A.J. (2007) Research Methods in Information. UK Facet Publ., London, p. 336.

[21] Pickard, A.J. (2013) Research Methods in Information. UK Facet Publ., London.

[22] Creswell, J. (2014) Research Design: Qualitative, Quantitative, and Mixed Methods Approaches. 4th Edition, Sage, Thousand Oaks, CA.

https://books.google.com/books?id=4uB76IC_pOQC\&pg=PA58\&source=gbs_select ed_pages\&cad $=3 \# \mathrm{v}=$ onepage\&q\&f$=$ false

[23] Bryman, A. (2015) Social Research Methods. 784.

[24] Tenopir, C., Birch, B. and Allard, S. (2012) Academic Libraries and Research Data Services: Current Practices and Plans for the Future. Library(Lond), 46, 61-75.

[25] Cohen, L., Manion, L. and Morrison, K. (2011) Research Methods in Education. Taylor \& Francis Group, Abingdon, p. 758.

[26] Surkis, A. and Read, K. (2015) Research Data Management. Journal of the Medical Library Association, 103, 154-156. https://doi.org/10.3163/1536-5050.103.3.011

[27] Brown, R.A., Wolski, M. and Richardson, J. (2015) Developing New Skills for Research Support Librarians. The Australian Library Journal, 64, 224-234.

https://doi.org/10.1080/00049670.2015.1041215

[28] Carlson, J. (2013) Opportunities and Barriers for Librarians in Exploring Data: Observations from the Data Curation Profile Workshops. Journal of eScience Librarianship, 2, e1042. https://doi.org/10.7191/jeslib.2013.1042 